\title{
A novel bio-inorganic bone implant containing deglued bone, chitosan and gelatin
}

\author{
G SARASWATHY, S PAL ${ }^{\dagger}, \mathrm{C}$ ROSE and T P SASTRY* \\ Bioproducts Laboratory, Central Leather Research Institute, Adyar, Chennai 600 020, India \\ ${ }^{\dagger}$ School of Bioscience and Engineering, Jadavpur University, Kolkata 700 032, India
}

MS received 20 April 2001; revised 14 June 2001

\begin{abstract}
With the aim of developing an ideal bone graft, a new bone grafting material was developed using deglued bone, chitosan and gelatin. Deglued bone (DGB) which is a by-product of bone glue industries and has the close crystallographic similarities of hydroxyapatite was used as main component in the preparation of bone implant. Chitosan was prepared from the exoskeleton of prawn (Pinaeus indicus, family Crustaceae) which is a by-product of seafood industries. Chitosan gives toughness to the product and do not allow the DGB particles to wither away when the implant is placed in the defect. Gelatin was used as binder for the preparation of DGBchitosan composite. The DGB, chitosan and DGB-chitosan-gelatin composite, which were prepared in the laboratory, were analysed for their physicochemical properties by infrared spectroscopy, X-ray diffraction and scanning electron microscopy studies.
\end{abstract}

Keywords. Bone graft; deglued bone; chitosan; gelatin.

\section{Introduction}

Calcium hydroxyapatite $\left[\mathrm{Ca}_{10}\left(\mathrm{PO}_{4}\right)_{6}(\mathrm{OH})_{2}\right]$ is the principal calcium phosphate used for biomedical applications. Hydroxyapatite (HA) is particularly interesting for implant purposes for its close similarities with mineral constituent of bone and tooth tissues. Many reports are available dealing with clinical uses of HA for jaw augmentation, tooth replacement, bone replacement and middle ear reconstruction (Uchida et al 1990; Cooke 1992). HA is available in market in many forms like solid blocks, microporous blocks and as granules.

HA implant of biological origin were also prepared and evaluated. Stefano et al (2000) compared the natural apatite prepared from compact bone with synthetic HA. The in vitro and in vivo studies showed that the natural apatite was well tolerated and has good osteoconductive properties than synthetic HA. Wafaa et al (1994) prepared HA from bovine bones and named it as veterinary HA (VHAP). They characterized the VHAP using infrared spectroscopy, X-ray diffraction studies and used the same in the construction of resected mandibles of rabbits with excellent results. In this study, we report the preparation of bioinorganic composite as bone implanting material using deglued bone (DGB), chitosan and gelatin.

DGB is a byproduct of bone glue industries. Crushed cattle bones are used as raw material in bone glue indus-

\footnotetext{
*Author for correspondence
}

tries. These crushed bones along with water are digested at 40 pounds per square inch (psi) steam pressure in bone digester for $36-48 \mathrm{~h}$. Almost all the protein (glue) gets digested at this pressure and the aqueous glue solution is withdrawn from the bottom of the digesters. Later, the glue solution is dried to flakes and these glue flakes are used in book binding and match industries. The deglued bones are sun dried and marketed as a mineral mixture that can be used as a fertilizer. This crude DGB retains the crystal structure of HA and an attempt has been made in this study to analyse the same and come to conclusion whether it can substitute the synthetic/coralline HA.

Chitosan is a polysaccharide with a structure similar to cellulose. The pure compound is the polymer form of 2 -amino-2-deoxy-D-glucose with a $1 \rightarrow 4$ - $\beta$-glucosidic bonding. The most important feature of chitosan is its biodegradability (Onishi and Machida 1999), flexibility and high resistance to heat due to intramolecular hydrogen bonds formed between hydroxyl and amino groups (Okuyama et al 1999).

Gelatin is a degraded form of collagen which is a connective tissue protein present in most of the vertebrates. Gelatin is well known for its wound healing properties. Sinha and colleagues (1972) treated burns with gelatin sheets and opined that these biological dressings prevented secondary infection and fluid loss due to exudation.

A composite biomaterial DGB-chitosan-gelatin is expected to show increased osteoconductivity and biodegradation together with sufficient mechanical strength for orthopaedic use. Different preparation methods of 
HA/chitosan composite have been reported, such as mixing of a HA powder in a chitosan solution and coating of HA particle onto a chitosan sheet (Varma et al 1999). However, the composites obtained by these means were microscopically inhomogenous and often caused inflammation when implanted.

The aim of present study is to prepare bioinorganic bone implant containing DGB, chitosan and gelatin and characterize for its physicochemical properties by infrared spectroscopy, X-ray diffractometry and scanning electron microscopy.

\section{Experimental}

\subsection{Materials}

The DGB, which is a by-product of bone glue industry, was collected from bone glue factory, situated nearby

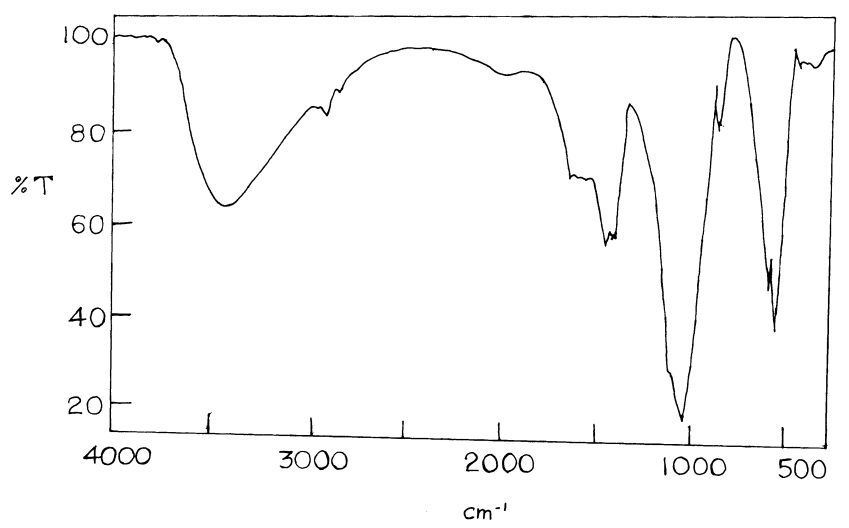

Figure 1. Infrared spectrum of DGB.
Vijayawada, Andhra Pradesh. Prawn (Pinaeus indicus, family: Crustaceae) shells were collected from local fish market. Gelatin, pharmaceutical grade was obtained from MBD gelatin, Mumbai.

2.1a Preparation of bone grafting material: (i) Purification and further deproteinization of DGB: The DGB pieces were washed with water to remove the impurities on the surface and autoclaved at about 15 psi steam pressure for $2 \mathrm{~h}$ to extract remaining protein. The autoclaved product was cooled, dried, powdered and sieved to a particle size in the range $75-750 \mu \mathrm{m}$, (ii) purification of chitosan from prawn shell: Chitosan was prepared by the modification of earlier methods (Mochizuki et al 1989). The prawn shells were cleaned thoroughly with water to remove sand and other impurities. Then the shells were treated with $5 \%$ sodium hydroxide solution for about $2 \mathrm{~h}$ for deproteinization. The product was washed well with water and treated with hydrochloric acid $(2 \mathrm{~N})$ for about $2 \mathrm{~h}$ to remove calcium carbonate. The resultant product was chitin. The pure chitin thus obtained was treated with $40 \%$ sodium hydroxide and heated in an oil bath containing castor oil at about $180^{\circ} \mathrm{C}$ for $2 \mathrm{~h}$. The contents were routinely checked for their solubility in hydrochloric acid $(0 \cdot 1 \mathrm{~N})$ solution. Once the contents were dissolved in hydrochloric acid, the same was removed from the bath, washed thoroughly with water and dried well. The resultant product was 'chitosan' and (iii) preparation of DGB, chitosan and gelatin composite: About $150 \mathrm{mg}$ of chitosan was dissolved in $6 \mathrm{ml}$ of hydrochloric acid $(0 \cdot 1 \mathrm{~N})$ at room temperature. The solution was denoted as ' $\mathrm{C}$ '. About $3 \mathrm{~g}$ of gelatin was dissolved in $6 \mathrm{ml}$ hydrochloric acid $(0 \cdot 1 \mathrm{~N})$ at $55^{\circ} \mathrm{C}$ in a water bath. This solution was denoted as ' $\mathrm{G}$ '. The solutions $\mathrm{C}$ and $\mathrm{G}$ were mixed

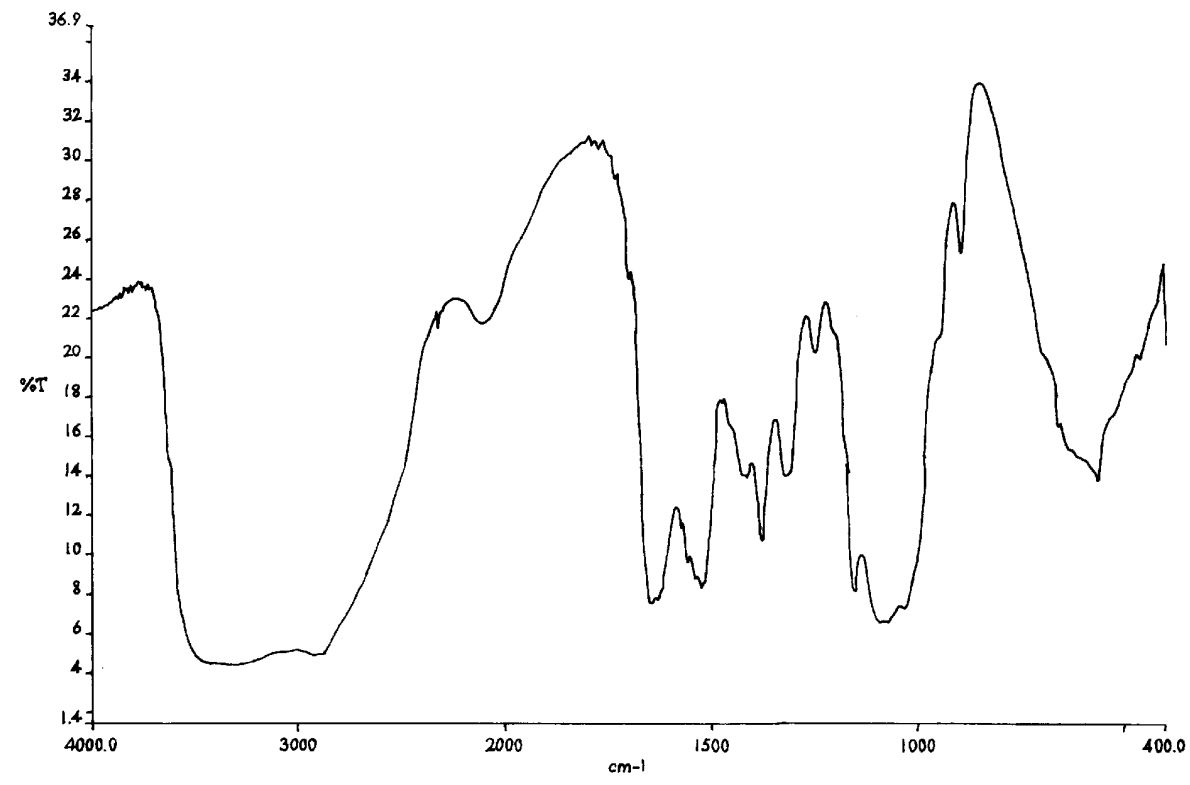

Figure 2. Infrared spectrum of chitosan. 
thoroughly at $55^{\circ} \mathrm{C}$ and denoted as ' $\mathrm{CG}$ '. About $12 \mathrm{~g}$ of DGB powder was mixed with $\mathrm{CG}$ and made into dough. It was then filled in a glass tube, diameter of $10 \mathrm{~mm}$ and extruded out with a glass rod. The cylindrical implants obtained were cut into required length and allowed to cure at room temperature for 2 to $3 \mathrm{~h}$. The cured samples were dried initially at $55^{\circ} \mathrm{C}$ overnight and finally at $100^{\circ} \mathrm{C}$ for $4 \mathrm{~h}$. The dried samples were sealed in polythene covers and sterilized by gamma-irradiation at 2 Mrads.

$2.1 \mathrm{~b}$ Evaluation of physicochemical properties: The physicochemical properties of the biomaterials that were prepared, were analysed by the following methods: (i) IR spectroscopy: The infrared spectra of DGB, chitosan gelatin and their composite were recorded on a Nicolet 360

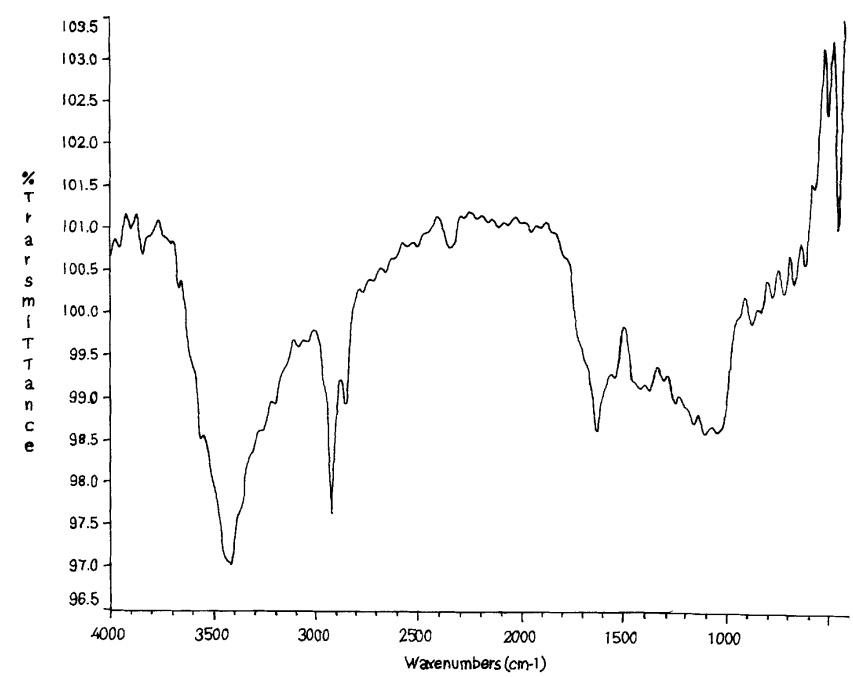

Figure 3. Infrared spectrum of gelatin.
Fourior transform infrared (FTIR) spectroscope using $\mathrm{KBr}$ pellet containing $2-6 \mathrm{mg}$ of sample. The infrared spectrum of DGB was compared with that of reference HA, (ii) X-ray diffraction: The DGB and composite were analysed on an Siemens 500 X-ray powder diffractometer in flat plane geometry using a source of copper $K \alpha$ of wavelength $1.5406 \AA$. The X-ray diffractogram of DGB was compared with X-ray diffraction indexed powder pattern for HA and (iii) SEM: Dried and powdered samples were coated with gold ions using an ion coater (fisons sputter coater) under the following condition: $0 \cdot 1$ Torr pressure, $20 \mathrm{~mA}$ current, and $70 \mathrm{~s}$ coating time. Surface structure was visualized by scanning electron microscope (SEM model LEICA stereoscan 440) using a $15 \mathrm{KV}$ accelerating voltage.

\section{Results and discussion}

\subsection{Infrared spectroscopy}

3.1a $D G B$ : The FTIR spectrum of DGB (figure 1) showed the peak of $-\mathrm{OH}$ group around $3500 \mathrm{~cm}^{-1}$ and $\mathrm{H}-\mathrm{O}-\mathrm{H}$ peak at $1650 \mathrm{~cm}^{-1}$. The peaks of the tetrahedral orthophosphate group were observed at 960, 1038, 620 and $560 \mathrm{~cm}^{-1}$. The carbonate peaks were seen around 1490 and $1420 \mathrm{~cm}^{-1}$. These peaks are well in accordance with those reported by Jianguo et al (1997).

3.1b Chitosan: The FTIR spectrum of chitosan (figure 2) shows a broad $-\mathrm{OH}$ stretching absorption band between 3450 and $3100 \mathrm{~cm}^{-1}$ and the aliphatic $\mathrm{C}-\mathrm{H}$ stretching between 2990 and $2850 \mathrm{~cm}^{-1}$. As the $-\mathrm{OH}$ stretching band and the aliphatic $\mathrm{C}-\mathrm{H}$ stretching band are aligned, it

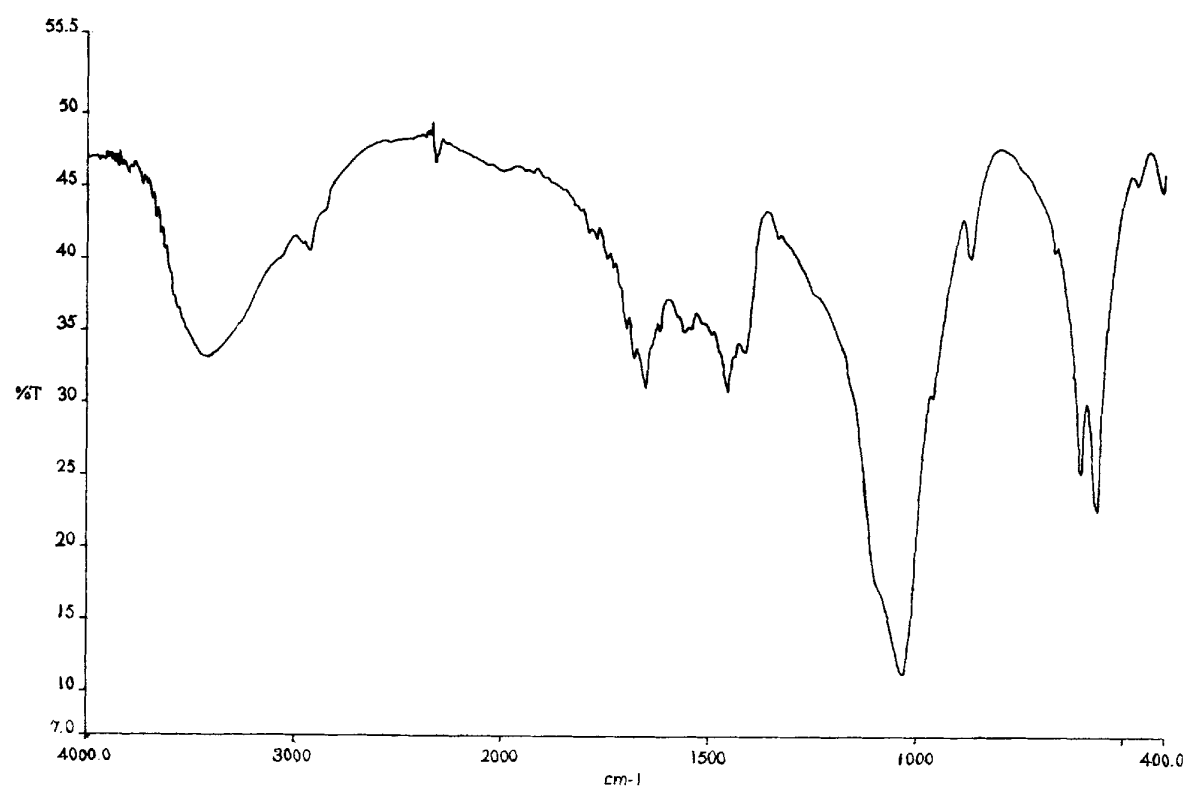

Figure 4. Infrared spectrum of DGB-chitosan-gelatin composite. 
appears as a broad band from 3450 and $2850 \mathrm{~cm}^{-1}$ in the spectrum. Another major absorption band between 1220 and $1020 \mathrm{~cm}^{-1}$ represents the free primary amino group $\left(-\mathrm{NH}_{2}\right)$ at $\mathrm{C}_{2}$ position of glucosamine, a major group present in chitosan. Peak at $1647 \mathrm{~cm}^{-1}$ represents acetylated amino group of chitin, which indicates that the sample is not fully deacetylated. Peak at $1384 \mathrm{~cm}^{-1}$ represents the $-\mathrm{C}-\mathrm{O}$ streching of primary alcoholic group $\left(-\mathrm{CH}_{2}-\mathrm{OH}\right)$.

3.1c Gelatin: As gelatin being a protein, the IR spectrum, shown in figure 3 , exhibits the characteristic amide absorption bands at $1660 \mathrm{~cm}^{-1}$ and $1550 \mathrm{~cm}^{-1}$.

3.1d Composite: The FTIR spectrum of DGB, chitosan and gelatin composite (figure 4) contains all the characteristic absorption peaks of DGB, chitosan, and gelatin. As there are no shifts of peaks of any group in the composite spectrum, it is confirmed that DGB-C-G composite is only a mixture and no chemical reaction has taken place between the individual components.

\section{$3.2 X$-ray diffraction}

3.2a $D G B:$ The X-ray diffractogram of DGB (figure 5a) is almost identical and in agreement with the indexed

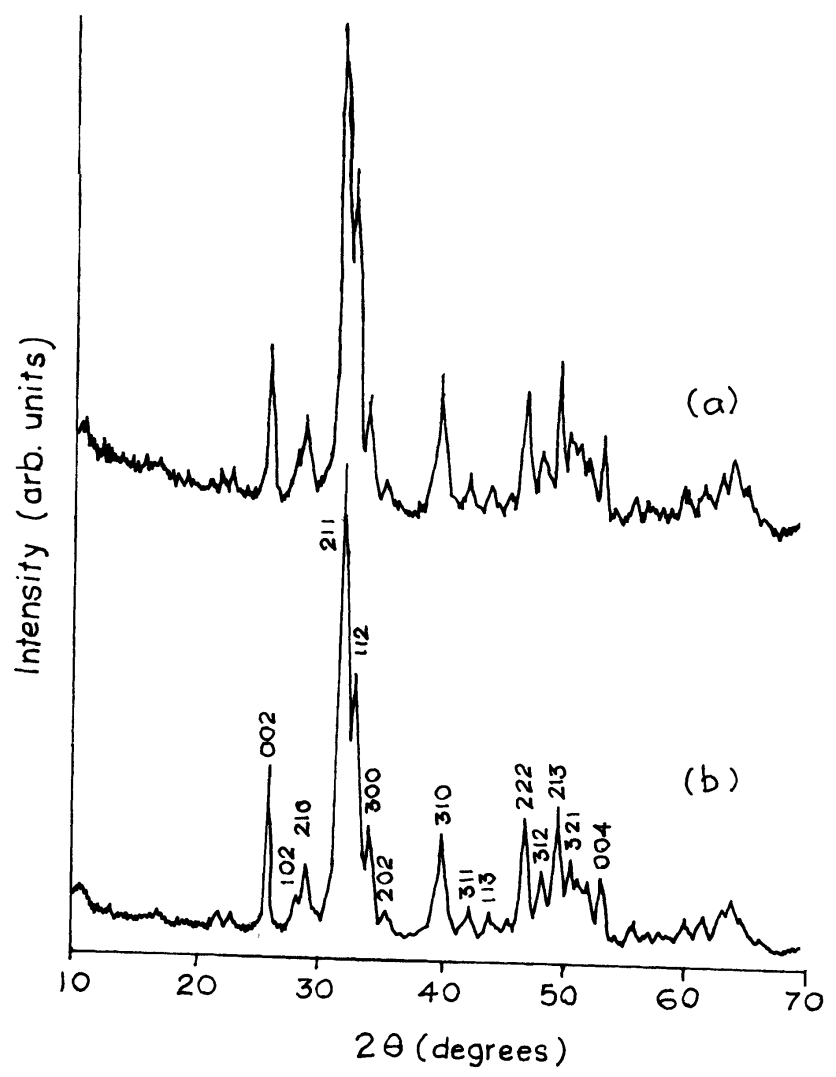

Figure 5. a. X-ray diffractogram of DGB and b. X-ray diffractogram of HA.
X-ray powder diffraction pattern (Tucker et al 1996) of standard HA (figure 5b) as recorded in Joint Committee on Powder Diffraction Standards (JCPDS), File No. 9-432. The well-resolved sharp diffraction peaks of the characteristic apatite moiety indicate high crystallinity of DGB. The peaks of HA were indexed based on hexagonal system and the cell parameters were calculated using the $d$-spacing of the indexed peaks. The $d$-spacing values were refined using least square refinement method. The hexagonal lattice parameters of DGB were listed in table 1 and they were found comparable to standard HA values.

3.2b Composite: The XRD pattern of DGB, chitosan, and gelatin composite, shown in figure 6 is similar to that of DGB and HA, except that the main peak around $31^{\circ}$ merges with each other. There is no change in crystallinity, indicating that the polymeric matrix of chitosan and gelatin does not interact with the HA lattice of DGB, during the composite preparation. The merging of 211 and 112 peaks in the composite is also reflected in the cell parameters. The cell parameters calculated for composite, listed in table 1 , show the reduction of $a$-axis and confirming the peak shift at the characteristic main region.

Thus, from the above observations, the DGB, chitosan and gelatin composite prepared was proved to retain its HA lattice without any change in crystallinity, the small

Table 1. X-ray diffraction data.

\begin{tabular}{lccc}
\hline Lattice parameters & JCPDS: 9-432 & DGB & Composite \\
\hline $\mathrm{A}$ & $9.418 \AA$ & $9.414 \AA$ & $9.406 \AA$ \\
$\mathrm{C}$ & $6.886 \AA$ & $6.886 \AA$ & $6.880 \AA$ \\
\hline
\end{tabular}

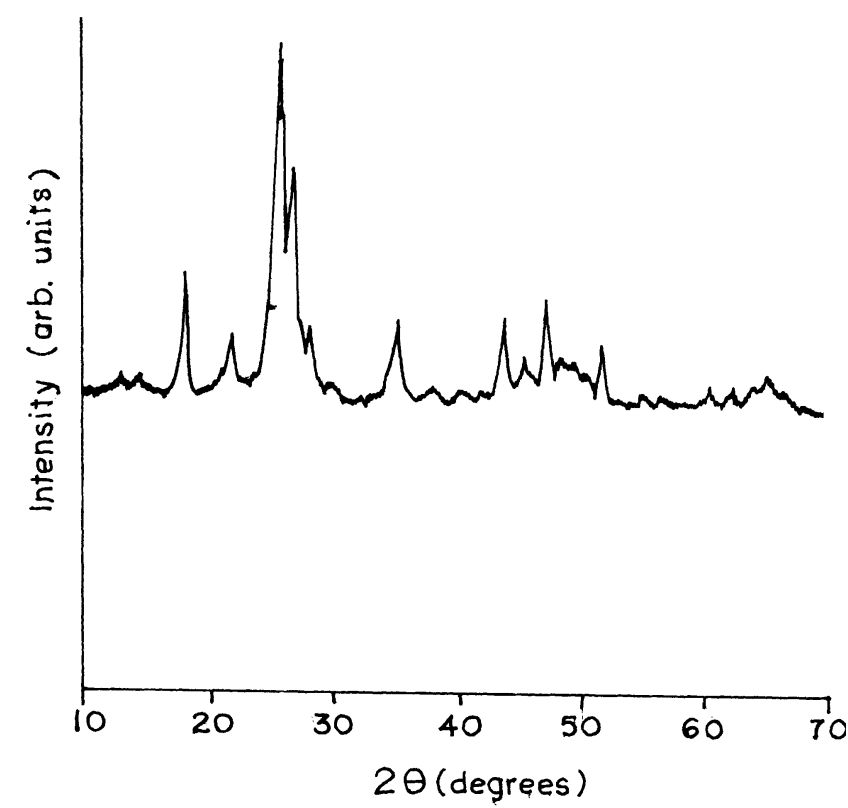

Figure 6. X-ray diffractogram of DGB-chitosan-gelatin composite. 


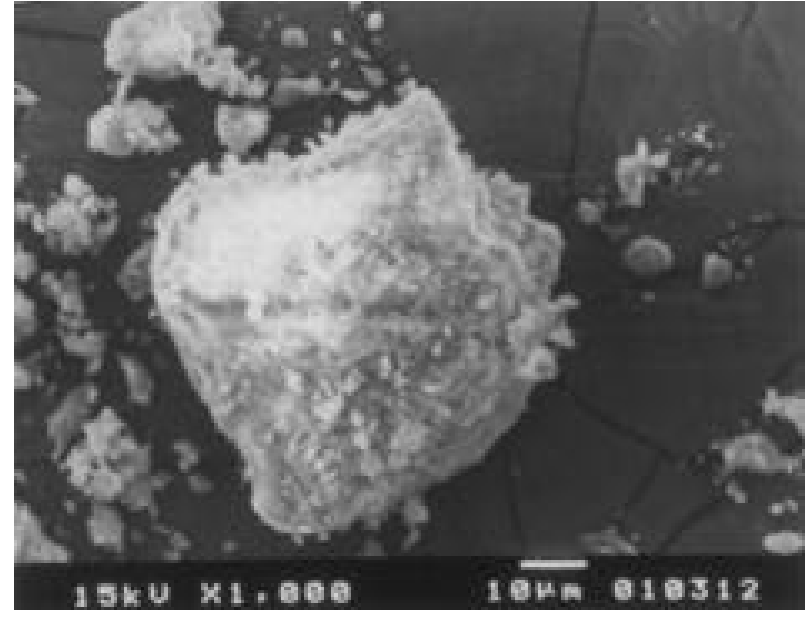

Figure 7. Scanning electron micrograph of DGB $(\times 1000)$.

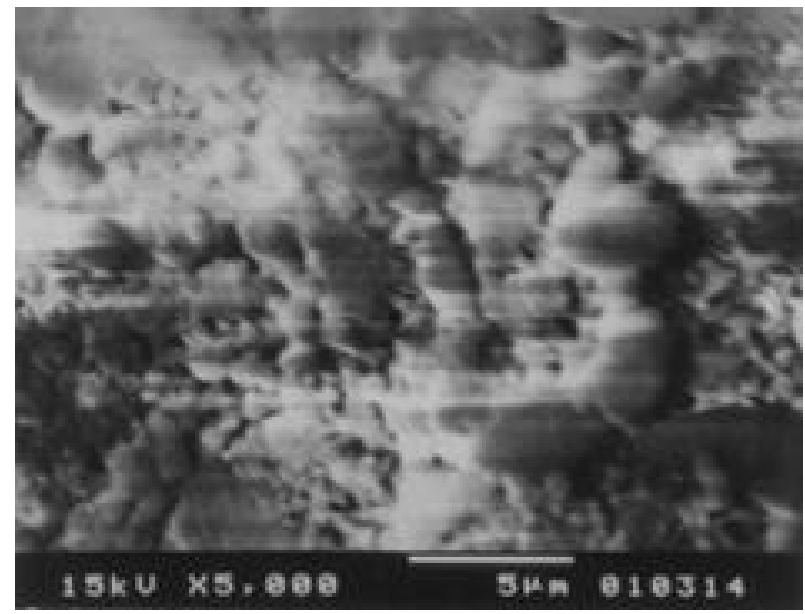

Figure 8. Scanning electron micrograph of DGB $(\times 5000)$.

reduction in $a$-axis can be accounted due to polymetric matrix in HA.

\subsection{Scanning electron microscopy}

Figures 7 and 8 show the SEM pictures of DGB at different magnifications. Figures 9 and 10 show the SEM pictures of DGB-C-G composite. These SEM pictures show that there is non-significant difference between the morphology of DGB and composite in dried and powdered form. But it can be observed that there is a coating of rough porous surface of DGB by chitosan and gelatin in case of composite.

\section{Conclusion}

As the implant contains DGB which has the close crystallographic similarities of HA and biocompatible and also

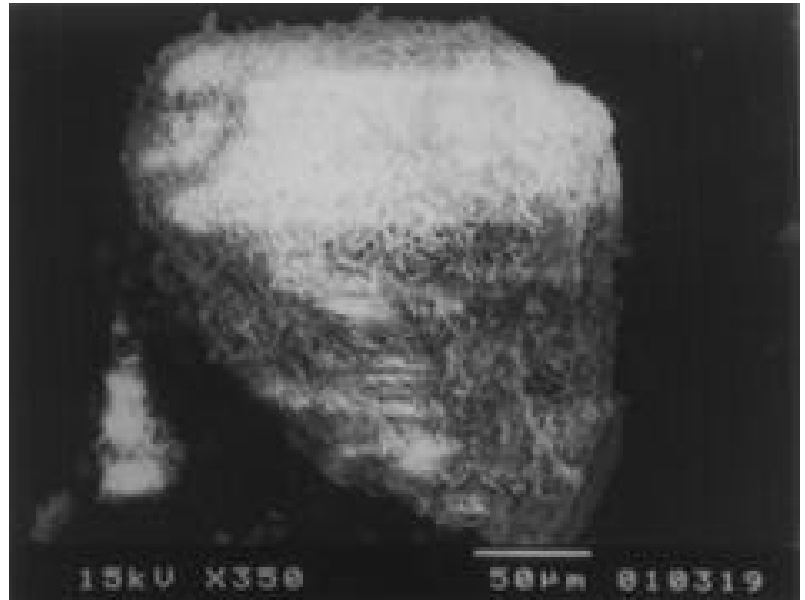

Figure 9. Scanning electron micrograph of DGB-chitosangelatin composite $(\times 350)$.

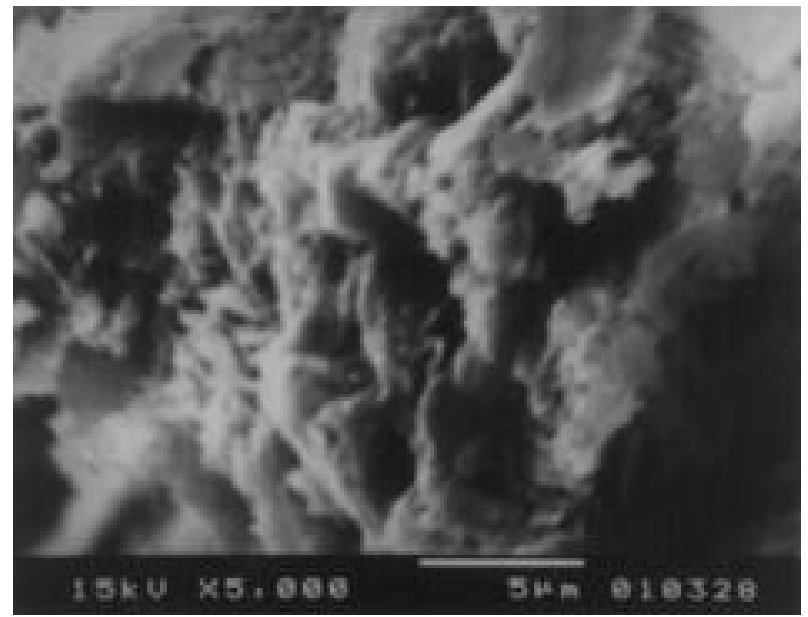

Figure 10. Scanning electron micrograph of DGB-chitosangelatin composite $(\times 5000)$.

bioactive materials like chitosan and gelatin, the same will be suitable as grafting material for orthopedic defects. As no chemical reaction occurred between the individual components, the original characteristics are not lost, thereby the graft as a whole will be an effective osteoinductive material. Further, in vivo studies are in progress to study the efficacy of DGB-C-G composite as an osteoinductive material using dogs as experimental animal models.

\section{References}

Cooke F W 1992 Clin. Ortho. Rel. Res. 27135

Jianguo Li, Haihong Liao and Malena S 1997 Biomaterials 18 743

Mochizuki A, Sato V, Ogawara H and Vamashita S 1989 J. Appl. Polym. Sci. 373375

Onishi H and Machida Y 1999 Biomaterials 20175 
Okuyama K, Noguchi K, Hanafusa Y, Osawa K and Ogawa K 1999 Int. J. Biol. Macromol. 26285

Stefano Guizzardi 2000 J. Biomed. Mater. Res. 53227

Sinha R N, Varma D K and Madan P 1972 J. Plastic and Reconstructive Surgery 556

Tucker B E, Cottel C M, Auyering R C V, Spector M and Nicollas G H 1996 Biomaterials 17631
Uchida A, Araki N, Shinto Y, Yoshikawa H, Ono K and Kurisaki E 1990 J. Bone Joint Surgery 72-B 298

Varma H K, Yokogawa Y, Espinosa F F, Kawamoto Y, Nishizawa K, Nagata F and Kameyama T 1999 Biomaterials 20 879

Wafaa I A F, Oscris W G, Shamael S M and Khalil M R 1994 Biomaterials 15609 